\title{
EDITORIAL
}

\section{From surgical to molecular scalpel: ERJ lung cancer series for 2009}

\author{
C. Brambilla
}

D espite progress in tobacco control, at least in industrialised countries, lung cancer will remain the leading killer among cancers for the next decade. However, translation of molecular carcinogenesis discoveries to the clinical setting gives realistic hope of major improvements in early diagnosis and will, furthermore, enable therapy to be tailored thus reducing the mortality rate. Tobacco exposure accounts for $85-90 \%$ of lung cancer deaths [1]. This range corresponds to $16,000-24,000$ lung cancer deaths in the USA that are not attributable to tobacco carcinogens. Lung cancer in nonsmokers could, therefore, rank among the seven to nine most fatal cancers in the USA [2]. An important study, of more than 630,000 people for incidence and 1.8 million people for mortality, has highlighted the major role of tobacco in lung cancer as its primary result and showed neither a temporal trend in favour of an increased incidence of lung cancer in nonsmokers nor a higher incidence in females, but supported claims that the death rate in males is higher than that in females; it also showed that further studies into the high incidence of lung cancer among females in Pacific Rim countries are necessary [2]. If tobacco exposure remains the main cause, lung cancer in nonsmokers should always be kept in mind, since carcinogenesis and, probably, treatment modalities differ.

Lung cancer results from the association of genetic susceptibility [3] and accumulation of molecular genetic and epigenetic abnormalities under known (tobacco) or unknown carcinogen exposure throughout the cancerisation field, as represented by the respiratory tract [4]. The natural history of the different types of lung cancer, other than a generally fast and fatal progression, is actually unknown. This is particularly obvious for the adenocarcinomas, in which a single TNM stage can characterise a wide range of growth and progression. While a more precise molecular classification is awaited, a subclassification on histological grounds seems necessary [5].

The 2009 series on lung cancer, beginning in the present issue of the European Respiratory Journal (ERJ), will probably raise more questions than allow definitive conclusions, but the advancement of so many studies represents a milestone of evaluated data, generally acquired in multidisciplinary approaches by clinicians and biologists. This series will cover

\section{STATEMENT OF INTEREST: None declared.}

CORRESPONDENCE: C. Brambilla, Institut Albert Bonniot, INSERM U823, Université Joseph Fourier, 38000 Grenoble, France. Fax: 33 476765834. E-mail: christian.brambilla@ujf-grenoble.fr the many facets of fighting lung cancer, from advances in staging via state of the art in positron emission tomography/ computed tomography scan practices, as reviewed in this issue [6], to the frontiers of upfront "omics" applied to diagnosis and therapy. The series authors are the experts in this field, as they have already written a large part of the whole story, and now they have kindly agreed to share their experience in a cooperative review, in order to give ERJ readers a transcontinental perspective.

The second article in the series will involve two expert thoracic surgeons from Japan and Spain [7] in order to investigate the possibility of performing "less than a lobectomy", particularly for the patients detected in early diagnosis programmes [8] or in randomised screening protocols [9]. The diagnosis and treatment of early proximal lung cancer will be reviewed by experts from three continents [10] in order to delineate the indications of local treatmen,t as well as innovative techniques exploring the bronchial wall beyond the ocular level. Since patients are still mainly treated by chemotherapy and, if needed, chemotherapy associated with radiotherapy for locally advanced tumours, European experts from four centers will share the task of describing the state of the art for advanced disease [11, 12] and multimodality treatment for locally advanced cancers [13]. Tailored therapy relying on the definition of molecular targets represents a major hope for the improvement of results in terms of response and overall survival associated with fewer sideeffects. The first molecules or antibodies are now being prescribed in clinical settings and dozens of new drugs are at different stages in the pipeline of development; two centers, in France and the USA, will provide their expertise in targeted therapy of nonsmall cell lung cancers [14, 15]. The molecular scalpels we intend to use against this wild killer need to be not only perfectly sharpened but also guided to the chinks in the armour.

International experts from four centers will gather together their knowledge in the field of molecular pathology [16, 17], in which two leaders started the fight many years ago, and bring together innovative concepts in the signalling pathway abnormalities of tumours to allow, by using validated biomarkers, a Trojan horse approach for early detection and targeted therapy. Two young and bright translational researchers $[18,19]$ will review the high throughput techniques being developed in cohorts of volunteers and that will soon be applied to patient care.

To really eradicate lung cancer it is mandatory to get to the root of the problem and define the characteristics of the stem cells 
that give birth to the disease; for this, the animal model of human lung cancer is the best approach [20]. The discovery and validation of these molecular scalpels needs a prospective reflection to define a coordinated strategy. The person in charge of the TP53 databank [21], which gathers all the published mutations found on this genome, will focus his expertise on the predictive abnormalities related to lung cancer. The principal investigator of the European Early Lung Cancer programme [22] will provide the first results of 5 yrs of coordinated efforts from the 12 programme centers' clinicians and biologists, who have gathered and explored information from 2,500 patients, and controlled and constituted a precious biological resource centre.

The European Respiratory Journal 2009 lung cancer series will provide readers with a cutting edge overview of the major advances in clinical management, as well as a comprehensive approach to the translation of innovative genetic and epigenetic techniques to the practice of pulmonologists. The series will demonstrate that all these results come from a tight collaboration between clinicians and researchers. This collaboration must be enforced, and we hope this series will give clinicians the willingness to participate in the bioclinical protocols running throughout Europe and continue to fight against the tobacco epidemics.

\section{REFERENCES}

1 Landi MT, Consonni D, Rotunno M, et al. Environment And Genetics in Lung cancer Etiology (EAGLE) study: an integrative population-based case-control study of lung cancer. BMC Public Health 2008; 8: 203.

2 Thun MJ, Hannan LM, Adams-Campbell LL, et al. Lung cancer occurrence in never smokers: an analysis of 13 cohorts and 22 cancer registry studies. PLoS Medicine 2008; 5: e185.

3 Hung RJ, McKay JD, Gaborieau V, et al. A susceptibility locus for lung cancer maps to nicotinic acetylcholine receptor subunit genes on 15q25. Nature 2008; 452: 633-637.

4 Brambilla C, Fievet F, Jeanmart M, et al. Early detection of lung cancer: role of biomarkers. Eur Respir J 2003; 21: Suppl. 39, 36S-44S.

5 Travis WD, Garg K, Franklin WA, et al. Bronchioloalveolar carcinoma and lung adenocarcinoma: the clinical importance and research relevance of the 2004 World Health Organization pathologic criteria. J Thorac Oncol 2006; 1: Suppl. 9, S13-S19.

6 De Wever W, Stroobants S, Coolen J, Verschakelen JA. Integrated PET/CT in the staging of nonsmall cell lung cancer: technical aspects and clinical integration. Eur Respir J 2009; 33: 201-212.

7 Rami-Porta R, Ball D, Crowley J, et al. The IASLC Lung Cancer Staging Project: proposals for the revision of the T descriptors in the forthcoming (seventh) edition of the TNM classification for lung cancer. J Thorac Oncol 2007; 2: 593-602.

8 International Early Lung Cancer Action Program Investigators, Henschke CI, Yankelevitz DF, et al. Survival of patients with stage I lung cancer detected on CT screening. $N$ Engl J Med 2006; 355: 1763-1771.

9 Wang Y, van Klaveren RJ, van der Zaag-Loonen HJ, et al. Effect of nodule characteristics on variability of semiautomated volume measurements in pulmonary nodules detected in a lung cancer screening program. Radiology 2008; 248: 625-631.

10 Kennedy TC, McWilliams A, Edell E, et al. Bronchial intraepithelial neoplasia/early central airways lung cancer: ACCP evidence-based clinical practice guidelines (2nd edition). Chest 2007; 132: Suppl. 3, 221S-233S.

11 Berghmans T, Van Houtte P, Paesmans M, et al. A phase III randomised study comparing concomitant radiochemotherapy as induction versus consolidation treatment in patients with locally advanced unresectable non-small cell lung cancer. Lung Cancer 2008 [Epub ahead of print: PMID 18804894].

12 Moro-Sibilot D, Barlesi F, Timsit JF, et al. Comment traiter la rechute du CBNPC après une chirurgie et chimiothérapie? Étude randomisée de phase III IFCT 0702. [How to treat the relapse of NSCLC after surgery and chemotherapy? IFTC 0702 randomized phase III study]. Rev Mal Respir 2008; 25: 91-96.

13 Vansteenkiste J. Improving patient management in metastatic non-small cell lung cancer. Lung Cancer 2007; 57: Suppl. 2, S12-S17.

14 Mountzios G, Planchard D, Besse B, et al. Mitogenactivated protein kinase activation in lung adenocarcinoma: a comparative study between ever smokers and never smokers. Clin Cancer Res 2008; 14: 4096-4102.

15 Lee MJ, Kim YS, Kummar S, Giaccone G, Trepel JB. Histone deacetylase inhibitors in cancer therapy. Curr Opin Oncol 2008; 20: 639-649.

16 Merdzhanova G, Edmond V, De Seranno S, et al. E2F1 controls alternative splicing pattern of genes involved in apoptosis through upregulation of the splicing factor SC35. Cell Death Differ 2008 [Epub ahead of print: PMID 18806759].

17 Shivapurkar N, Stastny V, Okumura N, et al. Cytoglobin, the newest member of the globin family, functions as a tumour suppressor gene. Cancer Res 2008; 68: 7448-7456.

18 Massion PP, Zou Y, Chen $\mathrm{H}$, et al. Smoking-related genomic signatures in non-small cell lung cancer. $A m J$ Respir Crit Care Med 2008 [Epub ahead of print: PMID 18776155].

19 Thomas RK, Baker AC, Debiasi RM, et al. High-throughput oncogene mutation profiling in human cancer. Nat Genet 2007; 39: 347-351.

20 Meuwissen R, Berns A. Mouse models for human lung cancer. Genes Dev 2005; 19: 643-664.

21 Marcel V, Hainaut P. p53 isoforms - a conspiracy to kidnap p53 tumour suppressor activity? Cell Mol Life Sci 2008 [Epub ahead of print: PMID 18854945].

22 Smith RA, Field JK, Duffy SW. A global approach to cancer-screening trials. Lancet Oncol 2008 [Epub ahead of print: PMID 18805732]. 